\title{
Sperm transport after non-surgical intrauterine insemination with frozen semen in ewes treated with prostaglandin F-2a
}

\author{
Y. Fukui and E. M. Roberts \\ School of Wool and Pastoral Sciences, The University of New South Wales. \\ Kensington, New South Wales, Australia, 2033
}

It has been suggested that poor fertilization rates in sheep treated with progestagens are due to an effect on sperm transport (Hancock, 1962; Quinlivan \& Robinson, 1969; Hawk \& Conley, 1972). Hawk (1973) considered that treatment with prostaglandin (PG) F-2 $\alpha$ also affected sperm transport adversely, but Edqvist, Einarsson \& Gustafsson (1975) have reported that more spermatozoa are present in the uterus and oviducts of PG-treated sheep $10 \mathrm{~min}$ after insemination with frozen-thawed semen. Fukui \& Roberts $(1976 a, b)$ found that intrauterine insemination by a method similar to that of Andersen, Aamdal \& Fougner (1973) resulted in comparable rates of fertilization and lambing when frozen-thawed and fresh-undiluted semen were used.

The aims of the present experiment (11-21 June 1975) were to determine whether treatment with PGF-2 $\alpha$ affects the pattern of sperm transport in sheep and whether non-surgical intrauterine insemination with frozen-thawed semen increases the number of spermatozoa that can be recovered from the oviducts.

The 226 mature Merino ewes were run with 12 mature vasectomized Merino rams which had been electroejaculated to prove the absence of spermatozoa. Between Days 7 and 11 of the oestrous cycle, 57 ewes were given a single intramuscular injection of $16 \mathrm{mg}$ PGF-2 $\alpha$ tromethamine salt (11.92 mg pure PGF-2 $\alpha$ : Upjohn Ltd, U.S.A.) in $1.0 \mathrm{ml} 0.9 \%(\mathrm{w} / \mathrm{v}) \mathrm{NaCl}$ solution. The remaining 169 ewes were untreated. Oestrous ewes in the treated and untreated groups were identified at 08.00 , $13.00,17.00$ and $23.00 \mathrm{~h}$ on each of the 5 days after treatment.

Semen was collected by an artificial vagina from 2 mature Merino rams. All ejaculates were examined immediately after collection and only those with a good initial sperm motility were used, freshly without dilution or after freezing and thawing. Pooled semen samples were diluted 1:2 with a diluent (pH 7.0) containing $360 \mathrm{~mm}$-tris, $33.3 \mathrm{~mm}$-glucose and $113.7 \mathrm{~mm}$-citric acid (Visser \& Salamon, 1974). Egg yolk and glycerol were added to give concentrations of 18 and $6 \%$ respectively. Freezing, pelleting and thawing of the semen were performed by the methods described by Visser \& Salamon $(1973,1974)$. The pelleted semen was stored in liquid nitrogen for 7-10 months.

All ewes were inseminated artificially once between 10 and $23 \mathrm{~h}$ after the detection of oestrus. The inseminating sample containing about $350 \times 10^{6}$ motile spermatozoa was $0.1 \mathrm{ml}$ for freshundiluted semen and $0.3 \mathrm{ml}$ for frozen-thawed semen. Fresh-undiluted semen was deposited into the external os of the cervix with the aid of a duck-billed speculum and headlight. Frozen-thawed semen was used similarly or placed within the uterus. For the latter, each ewe was kept standing in an insemination crate. The duck-billed speculum was inserted gently into the vagina and the external os of the cervix was located by using a headlight. The cervix was gripped by long $(30 \mathrm{~cm})$ forceps and a ball-tipped 17-gauge hypodermic needle, $10 \mathrm{~cm}$ long, attached to an inseminating pipette (Fukui \& Roberts 1976b) was introduced through the external orifice into the cervical canal. After withdrawal of the speculum, the semen was deposited into the uterus by the method of Andersen et al. (1973).

Of the 57 treated ewes $37(64.9 \%$ ) exhibited oestrus within 5 days of the PGF- $2 \alpha$ and this proportion compared well with the $29.6 \%(50 / 169)$ of control ewes which became oestrus within the period of study (i.e. about $60 \%$ if a complete oestrous cycle of 16.5 days had been followed). The numbers of ewes ovulating in the two groups were also similar, being 19/21 treated ewes and 18/21 control ewes. Twenty-one out of 37 and 21 out of 50 oestrous ewes were killed from the treatment and control groups; the remaining animals were not further considered. Insemination attempts 
were made with 20 treated ewes and 13 control ewes before the requisite 7 ewes in each group had been inseminated by deposition of semen in the uterus.

The ewes were killed, $24 \pm 1 \mathrm{~h}$ after insemination, by intracardiac injection of 20-30 ml sodium pentobarbitone $(60 \mathrm{mg} / \mathrm{ml}$ : Nembutal, Abbott Laboratories Ltd, Australia). Each segment of the tract was flushed separately with $0.9 \% \mathrm{NaCl}$ solution according to the method of Allison \& Robinson (1972). The techniques (staining, mounting and counting) of Quinlivan \& Robinson (1969) were used to determine the numbers of spermatozoa in the oviducts, uterus and cervix. Analyses of

Table 1. The number of spermatozoa (those intact in parentheses) in various parts of the reproductive tract of ewes inseminated by different methods after natural oestrus or an oestrus induced by treatment with PGF-2 $\alpha$

\begin{tabular}{|c|c|c|c|c|c|c|}
\hline \multirow[b]{2}{*}{ Treatment } & \multirow[b]{2}{*}{ Semen } & \multirow{2}{*}{$\begin{array}{l}\text { Insemination } \\
\text { technique }\end{array}$} & \multirow{2}{*}{$\begin{array}{l}\text { No. of } \\
\text { ewes }\end{array}$} & \multicolumn{3}{|c|}{$\begin{array}{c}\text { Total no. of spermatozoa }\left(\times 10^{3}\right) \\
\text { recovered from: }\end{array}$} \\
\hline & & & & Cervix & Uterus & Oviducts \\
\hline \multirow[t]{3}{*}{ PGF-2 $\alpha$} & Fresh- & Cervical & 7 & $882 \cdot 9$ & $132 \cdot 2$ & $79.7(77 \cdot 9)$ \\
\hline & $\begin{array}{l}\text { Frozen- } \\
\text { thawed } \\
\text { Frozen- }\end{array}$ & Cervical & 7 & $18 \cdot 2$ & 3.9 & $1.8(0.7)$ \\
\hline & $\begin{array}{l}\text { thawed } \\
\text { Total }\end{array}$ & Intrauterine & $\begin{array}{r}7 \\
21\end{array}$ & $\begin{array}{r}4.0 \\
905 \cdot 1\end{array}$ & $\begin{array}{r}20 \cdot 6 \\
156 \cdot 7\end{array}$ & $\begin{array}{r}3.5(2.2) \\
85.0(80.8)\end{array}$ \\
\hline \multirow[t]{4}{*}{ Control } & Fresh- & Cervical & 7 & $859 \cdot 3$ & $444 \cdot 7$ & $22.5(20.5)$ \\
\hline & $\begin{array}{l}\text { Frozen- } \\
\text { thawed }\end{array}$ & Cervical & 7 & $8 \cdot 8$ & 3.8 & $1.6(0.3)$ \\
\hline & $\begin{array}{l}\text { Frozen- } \\
\text { thawed }\end{array}$ & Intrauterine & 7 & $14 \cdot 1$ & $11 \cdot 5$ & $1.7(1.0)$ \\
\hline & Total & & 21 & 882.2 & $460 \cdot 0$ & $25.8(21.8)$ \\
\hline
\end{tabular}

Table 2. Results (F value) of analysis of variance on the $\log _{10}$ numbers of spermatozoa (those intact in parentheses) in various parts of the genital tract of ewes after different methods of insemination

(a) Comparison between three different methods of insemination

\begin{tabular}{lccc}
\hline \multirow{2}{*}{$\begin{array}{c}\text { Source of variation } \\
\text { (d.f.) }\end{array}$} & \multicolumn{3}{c}{ Spermatozoa recovered from: } \\
\cline { 2 - 4 } & Cervix & Uterus & \multicolumn{1}{c}{ Oviducts } \\
\hline Treatment (1) & 0.03 & 0.11 & $1.00(0 \cdot 51)$ \\
Semen and methods (2) & $32.17^{* * *}$ & $12.98^{* * *}$ & $6.00^{* *}\left(10 \cdot 30^{* * *}\right)$ \\
Interaction (2) & 0.43 & 0.28 & $0.21(0 \cdot 13)$ \\
Error (36): mean square & 0.58 & 0.53 & $0.29(0.67)$ \\
\hline
\end{tabular}

** $P<0.01 ; * * * P<0.001$.

(b) Comparison between cervical and intrauterine insemination with frozenthawed semen

\begin{tabular}{lccc}
\hline \multirow{2}{*}{$\begin{array}{c}\text { Source of variation } \\
\text { (d.f.) }\end{array}$} & \multicolumn{3}{c}{ Spermatozoa recovered from: } \\
\cline { 2 - 4 } & Cervix & Uterus & \multicolumn{1}{c}{ Oviducts } \\
\hline Treatment (1) & 0.13 & 0.00 & $3.50(0.82)$ \\
Semen and methods (1) & 0.43 & $12.20^{* * *}$ & $3.20\left(13.00^{* * *}\right)$ \\
Interaction (1) & 0.68 & 0.71 & $0.40(0.20)$ \\
Error (24): mean square & 0.63 & 0.28 & $0.10(0.49)$ \\
\hline
\end{tabular}

*** $P<0.001$. 
variance were conducted on the $\log _{10}$ numbers of spermatozoa counted and +1 was used to replace zero values.

The results of the sperm counts are shown in Table 1. There were no differences in the numbers of spermatozoa recovered from any parts of the tract of the PGF-2 $\alpha$-treated or the control animals. There were, however, statistically significant differences between the groups when the cervical and intrauterine insemination methods with frozen-thawed semen were compared for the numbers of spermatozoa in the uterus (Table $2 b$ ). The higher numbers of uterine spermatozoa after deposition of semen directly into the uterus would be expected, but the higher numbers of cervical spermatozoa in the control than in the treated ewes after intrauterine insemination may be due to uterine contractions caused by the PGF-2 $\alpha$ treatment. This is unlikely, however, because of the rapid disappearance of PGF-2 $\alpha$ from the circulation after i.m. injection (Raz, 1972). When PGF-2 $\alpha$ is added to semen before insemination or is administered intramuscularly $10 \mathrm{~min}$ after insemination, higher numbers of spermatozoa are recovered from the oviducts (Edqvist et al., 1975).

These results show that the pattern of sperm transport was not affected by PGF-2 $\alpha$ treatment but that non-surgical intrauterine insemination with frozen-thawed semen appeared to increase the number of spermatozoa recovered from the oviducts. Moreover, far more $(P<0.001)$ of the spermatozoa in the oviducts were intact (i.e. not tailless) after intrauterine insemination ( $64 \%$ in treated group, $60 \%$ in controls) than after cervical insemination (37\% and $19 \%$, respectively). The impairment of sperm transport which has been observed after progestagen treatment of ewes (Quinlivan \& Robinson, 1967, 1969; Hawk \& Conley, 1972) does not occur when PGF-2 $\alpha$ is used to induce oestrus. The deposition of semen into the uterus by non-surgical methods would appear to increase the chances of the spermatozoa passing rapidly into the oviducts without damage or loss of fertilizing capacity.

We thank Dr J. W. Lauderdale, Upjohn Company, Kalamazoo, Michigan, U.S.A., for the supply of prostaglandin F-2 $\alpha$ and Dr S. Salamon, Department of Animal Husbandry, University of Sydney, for advice on techniques of freezing pelleted ram semen.

\section{References}

Allison, A.J. \& Robinson, T.J. (1972) The recovery of spermatozoa from the reproductive tract of the spayed ewe treated with progesterone and oestrogen. J. Reprod. Fert. 31, 215-224.

Andersen, K., Aamdal, J. \& Fougner, J.A. (1973) Intrauterine and deep cervical insemination with frozen semen in sheep. Zuchthygiene 8, 113-118.

Edquist, S., Einarsson, S. \& Gustafsson, B. (1975) Effect of PGF-2 $\alpha$ on sperm transport in the reproductive tract of the ewe. Acta vet. scand. 16, 149-151.

Fukui, Y. \& Roberts, E.M. (1976a) Studies of nonsurgical intra-uterine insemination of frozen-pelleted semen in the ewe. Proc. 8th Int. Congr. Anim. Reprod. \& A.I., Cracow, p. 85.

FukUI, Y. \& RoBERTs, E.M. (1976b) Fertility of nonsurgical intra-uterine insemination with frozenpelleted semen in ewes treated with prostaglandin F-2a. Proc. Int. Congr. Sheep Breed., Muresk, pp. $482-494$.

HANCOCK, J.L. (1962) Fertilization in farm animals. Anim. Breed. Abstr. 30, 285-310.

HAWK, H.W. (1973) Estrus, uterine motility and sperm transport after prostaglandin. J. Anim. Sci. 37, 314, Abstr.

HAWK, H.W. \& Conley, H.H. (1972) Investigation of sperm transport failures in ewes administered synthetic progestagen. J. Anim. Sci. 34, 609-613.

Quinlivan, T.D. \& Robinson, T.J. (1967) The number of spermatozoa in the fallopian tubes of ewes at intervals after artificial insemination following withdrawal of SC-9880-impregnated intravaginal sponges. In The Control of the Ovarian Cycle in the Sheep, pp. 177-194. Ed. T. J. Robinson. Sydney University Press.

Quinlivan, T.D. \& RoBinson, T.J. (1969) Numbers of spermatozoa in the genital tract after artificial insemination of progestagen-treated ewes. $J$. Reprod. Fert. 19, 73-86.

RAz, A. (1972) Interaction of prostaglandins with blood plasma proteins III. Rate of disappearance and metabolite formation after intravenous administration of free or albumin-bound prostaglandin F-2 $\alpha$ and A-2. Life Sci. 11, 965-974.

Visser, D. \& Salamon, S. (1973) Fertility of ram spermatozoa in a Tris-based diluent. Aust. J. biol. Sci. 26, 513-516.

Visser, D. SALAmon, S. (1974) Fertility following insemination with frozen-thawed reconcentrated and unconcentrated ram semen. Aust. J. biol. Sci. 27, $423-425$. 